\title{
The presence of Chlamydia phage PhiCPG1 capsid protein VP1 genes and antibodies in patients infected with Chlamydia trachomatis
}

\author{
Jingyue Ma†, Yuan Liư, Yuanjun Liu, Lingjie Li, Shuping Hou, Xibo Gao, Manli Qi and \\ Quanzhong Liu
}

Department of Dermatovenereology, Tianjin Medical University General Hospital, Tianjin 300052, China

\begin{abstract}
Chlamydia phage PhiCPG1 has been found in Chlamydia caviae in a guinea pig model for inclusion conjunctivitis, raising the possibility that Chlamydia phage is also present in patients infected with $C$. trachomatis $(\mathrm{Ct})$. In the present study, we assayed for presence of Chlamydia phage capsid protein VP1 genes and antibodies in 84 non-Ct controls and $206 \mathrm{Ct}$ patients using an enzymelinked immunoassay (ELISA), followed by verification with Western blot. None of the subjects were exposed to an antibiotic treatment or had a C. pneumoniae infection. The VP1 antibody test was positive in both, the ELISA and Western blot assay, in $4 \mathrm{Ct}$ patients. PCR amplification experiments revealed presence of the VP1 gene in $5 \mathrm{Ct}$ patients. The results suggest that Chlamydia phage capsid protein VP1 may exist in some Ct patients.
\end{abstract}

Key words: Chlamydia trachomatis, Chlamydia bacteriophage, capsid protein, VP1

Received: 07 September, 2015; revised: 30 December, 2015 accepted: 11 March, 2016; available on-line: 20 May, 2016

\section{INTRODUCTION}

Chlamydia trachomatis $(\mathrm{Ct})$ is one of the common pathogens in human reproductive tract infections, accounting for $40-50 \%$ of the most prevalent sexually transmitted diseases in the world (Marrazzo et al., 2014). Chronic chlamydial disease may lead to pelvic inflammatory disease, ectopic pregnancy, infertility and trachoma, the world's leading cause of preventable blindness (Kohlhoff et al., 2015). Resistance to antibiotics among Ct patients poses a serious problem to treatment, especially in regions of the world where Ct infection is endemic and highly prevalent (Keegan et al., 2014). This has led researchers to investigate the feasibility of using lytic phages to treat a $\mathrm{Ct}$ infection, just as bacteriophages have become an intriguing area of research as an alternative to antibiotics for other types of infection (Śliwa-Dominiak et al., 2013).

Six species of chlamydia phage have been identified

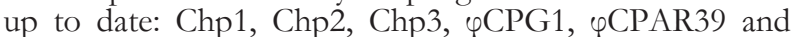
Chp4. All 6 species could infect Chlamydia, including C. psittaci, C. abortus, C. felis, C. caviae, C. pecorum, and C. pneumoniae (Pawlikowska-Warych et al., 2015). However, none have been shown to infect $C$. trachomatis. For assessment of similarity and differences between the species, two regions encoding protein VP1 and ORF4 are often used (Hsia et al., 2000; Everson et al., 2002; Sait et al., 2011). Garner and coworkers (2004) used VP1 monoclonal antibody 55 from Chp2 and PCR to achieve isolation, molecular characterization and the genome sequence of chlamydial bacteriophage Chp3 from C. pecorum. The capsid protein VP1 is highly conserved among different Chlamydia phage strains and mediates adhesion and entry into host cells (Hsia et al., 2000b). The present study examined whether the phage is also present in patients with a Ct infection.

\section{PATIENTS AND METHODS}

Patients. The study was approved by the Ethics Committee of Tianjin Medical University General Hospital (2014-YX-007). The requirement for an informed consent has been waived. The study included serum samples from $206 \mathrm{Ct}$ patients and 84 non-Ct control subjects treated as ambulatory patients at our hospital between 2008 and 2010. Patients and controls had shown no significant differences in age, gender distribution, or medical history (data not shown). None of the study participants had previously received an antibiotic therapy against the $\mathrm{Ct}$ infection. Patients had been diagnosed with the $\mathrm{Ct}$ infection using the McCoy culture assay involving columnar epithelium cells from the genitourinary tract. The cervical and urethral swabs were stored in $2 \mathrm{sp}$ solution $(68.46 \mathrm{~g} / \mathrm{L}$ sucrose, $1.09 \mathrm{~g} / \mathrm{L}$ $\mathrm{K}_{2} \mathrm{HPO}_{4}$, $30.9 \mathrm{ml} / \mathrm{L}$ fetal bovine serum, $50 \mathrm{mg} / \mathrm{L}$ streptomycin, $100 \mathrm{mg} / \mathrm{L}$ vancomycin, $250 \mathrm{mg} / \mathrm{L}$ amphotericin B) at $-80^{\circ} \mathrm{C}$. The patients' sera were initially screened in the outpatient department using a micro immunofluorescence assay to exclude patients with Chlamydia pneumoniae (Bennedsen et al., 2002).

Culture of PhiCPG1 phage and viral genomic DNA isolation. Chlamydia caviae guinea-pig inclusion conjunctivitis (GPIC) strains containing PhiCPG1 (Tianjin Institute of Sexually Transmitted Diseases, Tianjin, China) were grown for $48 \mathrm{~h}$ at $37^{\circ} \mathrm{C}$ in a McCoy cell culture system using Dulbecco's Modified Eagle Medium. Culture supernatants were collected and centrifuged at $30000 \times \mathrm{g}$ for $30 \mathrm{~min}$ at $4^{\circ} \mathrm{C}$, and then were filtered through a $0.22-\mu \mathrm{m}$ membrane (Schachter et al.,

\footnotetext{
e-mail: quanzhongliu_tj@163.com
}

${ }^{\dagger}$ The authors contributed equally to the work

Abbreviations: Ct, Chlamydia trachomatis; Vp1, viral protein 1; ELI$S A$, enzyme-linked immunoassay; $P C R$, polymerase chain reaction; ORF, opening reading frame; GPIC, Chlamydia caviae guinea-pig inclusion conjunctivitis; PBS, phosphate-buffered saline; SDS-PAGE, sodium dodecyl sulphate-polyacrylamide gel eletrophoresis; bp, base pair; pNPP, Disodium 4-nitrophenyl phosphate; TBST, Tris Buffered Saline With Tween; dNTP, deoxy-ribonucleoside triphosphate; IPTG, isopropylthio- $\beta$-D-galactoside; OD, optical density 
1994). Filtrates were treated with DNase I $(20 \mu \mathrm{g} / \mathrm{ml})$ for $1 \mathrm{~h}$ at $37^{\circ} \mathrm{C}$, and viral particles were centrifuged at $100000 \times g$ for $3 \mathrm{~h}$ at $4^{\circ} \mathrm{C}$. The pellet was treated with proteinase $\mathrm{K}(200 \mu \mathrm{g} / \mathrm{ml})$ for $1 \mathrm{~h}$ at $37^{\circ} \mathrm{C}$, after which single-stranded bacteriophage genomic DNA was extracted using phenol/chloroform and precipitated with ethanol. The isolated DNA was made double-stranded using the Klenow fragment and random hexamer priming. Second-strand synthesis was confirmed using an agarose gel mobility shift assay (Maass et al., 1995).

Cloning of VP1. The double-stranded genomic DNA was digested with BamHI to yield a single linearized molecule $(4.5 \mathrm{~kb})$. The region encoding VP1 was amplified by PCR using the forward primer 5'-AGTAGGGAAGCCATGGTYAGG-3' (including an NcoI site) and the reverse primer 5'-ACTGACTCGAGAT'TAGAAATGATCAAT-3' (including a XhoI site). The PCR reaction $(50 \mu \mathrm{l})$ contained $25 \mathrm{pmol}$ of each primer, $1 \mathrm{mM} \mathrm{MgSO}, 300 \mu \mathrm{M}$ dNTP, and $2.5 \mathrm{U}$ Platinum Pfu DNA polymerase. The following thermal cycling conditions were used: $95^{\circ} \mathrm{C}$ for $2 \mathrm{~min}$; followed by 35 cycles of $94^{\circ} \mathrm{C}$ for $15 \mathrm{~s}, 58^{\circ} \mathrm{C}$ for $30 \mathrm{~s}$, and $68^{\circ} \mathrm{C}$ for $2 \mathrm{~min}$; and finally $68^{\circ} \mathrm{C}$ for $10 \mathrm{~min}$ (Sambrook et al., 1989). The PCR product was checked by agarose gel electrophoresis. The gel-purified PCR product was digested with NcoI and XhoI and inserted into the pET30a $(+)$ vector (EMD Biosciences Novagen, Beijing, China), which added an $\mathrm{N}$-terminal His-tag to the VP1 sequence (pET-VP1).

Overexpression and purification of recombinant VP1. The pET-VP1 plasmid was transformed into Escherichia coli strain BL21 cells and positive clones were identified by antibiotic selection. The protein was overexpressed in BL21 cells after IPTG induction for $3 \mathrm{~h}$. Recombinant VP1 was purified from inclusion bodies by lysing the cells in phosphate-buffered saline (PBS), lysozyme, and 3\% Triton X-100 under sonication. The insoluble fraction was transferred to a fresh tube, resuspended in a binding buffer containing $6 \mathrm{M}$ urea, and sonicated again. The suspension was analyzed by SDSPAGE in $15 \%$ gels, run at $120 \mathrm{~V}$ for $1.5 \mathrm{~h}$, followed by Western blotting using mouse monoclonal antibody against the His-tag and peroxidase-conjugated sheep antimouse immunoglobulin G secondary antibody (Karunakaran et al., 2002).

After confirmation that positive clones were expressing the correct protein, the overexpression of recombinant VP1 was scaled up, and the protein was purified by nickel chelation column chromatography (CWBIO, Beijing, China). Loading and washing steps were conducted in the presence of $5 \mathrm{mM}$ imidazole, and VP1 was eluted with $500 \mathrm{mM}$ imidazole. Eluate was dialyzed extensively against PBS in bags with a $3.5-\mathrm{kDa}$ molecular weight cutoff. Dialysate was analyzed by SDS-PAGE and Coomassie G-250 staining, and protein was quantified by band densitometry (Laughton 1984).

Production of mouse anti-VP1 antibody. Animal experiments were approved by the Ethics Committee of Tianjin Medical University General Hospital and conducted in accordance with ARRIVE guidelines. Purified recombinant VP1 $(50 \mu \mathrm{g})$ in incomplete Freund's adjuvant was injected intraperitoneally into BALB/c mice, followed by two booster injections at 2 -week intervals. Sera were collected from inner canthal vein blood and analyzed for the presence of anti-VP1 antibodies by incubating with purified recombinant VP1 that had been fractionated by SDS-PAGE and transferred to nitrocellulose membranes. Antibody binding to VP1 was visualized using alkaline phosphatase-conjugated anti-mouse immunoglobulin G secondary antibody (Laemmli 1970).
Serological antibody screening for VP1 protein. The wells of a 96-well microtiter plate were coated overnight at $4^{\circ} \mathrm{C}$ with $10 \mu \mathrm{g} / \mathrm{ml}$ recombinant VP1 in a bicarbonate binding buffer ( $\mathrm{pH}$ 9.6). After three washes with PBS containing Tween-20 (PBST), the wells were blocked with $3 \%$ bovine serum albumin in PBST

$(100 \mu \mathrm{l} /$ well $)$ for $1 \mathrm{~h}$ at $37^{\circ} \mathrm{C}$, and then washed again three times with PBST (Claes et al., 2012). To identify the optimal sample dilution, serial dilutions from 1:50 to 1:6400 were prepared with immunized mouse sera as a positive control, and sera from some non-Ct subjects as a negative control, and aliquots $(100 \mu \mathrm{l})$ of the dilutions were incubated in the wells for $1 \mathrm{~h}$ at $37^{\circ} \mathrm{C}$. The wells were washed six times with PBST, then $100 \mu$ l of alkaline phosphatase-conjugated sheep anti-mouse $(1: 10,000)$ or anti-human immunoglobulin $G$ secondary antibodies (1:5000) in PBST were added and incubated for $1 \mathrm{~h}$ at $37^{\circ} \mathrm{C}$ (Hackett et al., 2010). Plates were washed six times with PBST, $100 \mu \mathrm{l}$ pNP substrate was added, and the plates were incubated in the dark for $30 \mathrm{~min}$. Reactions were terminated by adding $50 \mu \mathrm{l}$ of $1 \mathrm{M} \mathrm{NaOH}$ to the wells and optical density was measured at $405 \mathrm{~nm}$ with a microplate reader (Cohen et al., 2000). Recombinant VP1 was subjected to SDS-PAGE separation, transferred to nitrocellulose membranes, and then probed with immunized mice sera and ELISA-positive human sera at a 1:100 dilution with TBST containing $1 \%$ bovine serum albumin (Nolen et al., 2013). Membranes were incubated with alkaline phosphatase-conjugated sheep anti-mouse or anti-human immunoglobulin G secondary antibodies and washed. Binding was visualized using the BCIP/ NBT substrate (Sigma-Aldrich, Beijing, China).

Determination of the Vp1 gene sequence. The epithelial cells of genitourinary tract from $\mathrm{Ct}(+)$ and $\mathrm{Ct}(-)$ patient swabs were lysed and centrifuged to obtain the Ct genomic DNA. Pure solution of the Ct DNA was used as a template for a PCR reaction using primers designed based on a conserved sequence from the VP1 region of all the Chlamydia phages: forward primer 5'-CGGCGT'T'TGCCTTCAGT-3' and reverse primer 5'-GCGT'TGCCATACGTGCTA-3' which amplify a 196 bp fragment of the VP1 gene. A phiCPG1 plasmid served as a positive control, and twice boiled water was used as a negative control. PCR amplification consisted of 11 cycles of $45 \mathrm{~s}$ at $94^{\circ} \mathrm{C}, 40 \mathrm{~s}$ at $58^{\circ} \mathrm{C}$ and $45 \mathrm{~s}$ at $72^{\circ} \mathrm{C}$ (with each cycle the annealing temperature was decreased by $1^{\circ} \mathrm{C}$ ) and 20 cycles of $45 \mathrm{~s}$ at $94^{\circ} \mathrm{C}$, $30 \mathrm{~s}$ at $48^{\circ} \mathrm{C}$ and $45 \mathrm{~s}$ at $72^{\circ} \mathrm{C}$. The sequencing data obtained for the clinical specimens were analyzed by base sequence alignment with the target genomes of VP1using a gene software and BLAST searches.

\section{RESULTS}

\section{Cloning, expression and purification of recombinant VP1}

The PhiCPG1 phage major capsid protein VP1 was cloned from cultured GPIC strains containing PhiCPG1 into the pET-30a expression plasmid. The sequence of the insert used to produce the recombinant protein is consistent with a published VP1 sequence (GenBank GeneID 1261929). This protein was overexpressed in E. coli and visualized as a single band on a SDS-PAGE gel, consistent with the expected molecular weight of $70 \mathrm{kDa}$, and used to raise antibodies in mice. This recombinant protein and the sera from immunized mice were used to design and 
Table 1. ELISA detection of the anti-VP1 antibodies in sera from mice immunized with recombinant VP1 and in sera from non-Ct control patients.

\begin{tabular}{llll}
\hline & \multicolumn{3}{c}{ OD $_{405}$} \\
\hline Serum dilution & Immunized mice & Non-Ct controls & Blank \\
\hline $1: 50$ & 0.19 & 0.129 & 0.093 \\
\hline $1: 100$ & 0.125 & 0.115 & 0.057 \\
\hline $1: 200$ & 0.124 & 0.106 & 0.083 \\
\hline $1: 400$ & 0.121 & 0.099 & 0.087 \\
$1: 800$ & 0.116 & 0.101 & 0.103 \\
\hline $1: 1600$ & 0.098 & 0.094 & 0.084 \\
$1: 3200$ & 0.092 & 0.089 & 0.082 \\
$1: 6400$ & 0.089 & 0.098 & 0.096 \\
\hline
\end{tabular}

validate ELISA and Western blot techniques to probe the sera obtained from $\mathrm{Ct}$ patients for the presence of anti-VP1 antibodies.

\section{ELISA detection of anti-VP1 antibodies in Ct patients}

An ELISA was designed to detect the presence of anti-VP1 antibodies in the sera from Ct patients and non-Ct controls. In initial experiments to optimize sample dilution, a dilution of 1:400 gave the greatest difference in blank-corrected $\mathrm{OD}_{405}$ between the immunized mouse sera and non-Ct human sera (2.59fold, Table 1). Therefore this dilution was used for all subsequent ELISA tests. The cutoff for a positive ELISA was defined as the sum of $10 \%$ of the average blank-corrected $\mathrm{OD}_{405}$ for positive controls (0.035) and the average OD405 for the negative control (0.0135). The critical value (0.102) was the cutoff (0.016) plus the average background (0.086). Based on this threshold value, the ELISA detected anti-VP1 antibodies in 18 of $206 \mathrm{Ct}$ patients $(8.74 \%)$ and in 2 of 84 controls $\left(2.38 \% ; p<0.05, \chi^{2}\right.$ test $)$.

\section{Western blot detection of anti-VP1 antibodies}

ELISA-positive samples were subjected to Western blotting to confirm the presence of anti-VP1 antibodies. Four ELISA-positive $\mathrm{Ct}$ patient samples were found to be positive by a Western blot (Fig. 1).

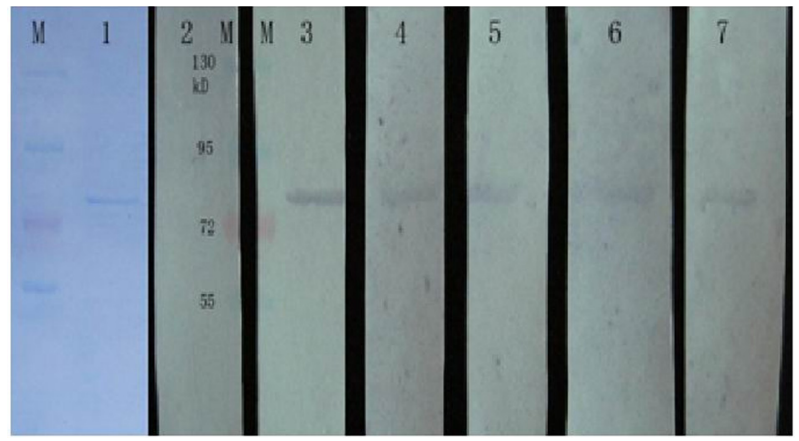

Figure 1. Western blot identification of recombinant VP1 in Ct patient sera.

Western blotting of purified preparations of recombinant VP1 $(70 \mathrm{kDa})$ using mouse or patient sera. $\mathrm{M}$, molecular weight markers. Lane 1, Coomassie-stained SDS-PAGE of purified VP1. Lane 2, the same VP1 preparation as lane 1 probed using serum from unimmunized mice. Lane $\mathbf{3}$, the same VP1 preparation as lane 1 probed using serum from immunized mice. Lanes 4-6, sera from four Ct patients that tested positive for VP1 by ELISA.

\section{PCR to detect the Vp1 gene}

The amplified $196 \mathrm{bp}$ fragments of the VP1 gene were acquired in five $\mathrm{Ct}$ patient swabs (Fig. 2). Sequencing results revealed a difference of only 4 to 5 bases between amplified fragment and the target $\mathrm{Vp} 1$ gene sequences. Blast analysis showed $>90 \%$ coverage and similarity with Chlamydia phage phiCPG1, chp4, CPAR39, chp3, chp2. The amplified Vp1 fragment was detected in swabs of the Western blot positive patients.

\section{DISCUSSION}

Chlamydia phages have been proposed as an alternative to antibiotics to treat a $\mathrm{Ct}$ infection. These lytic phages infect only Chlamydia and they kill their host during growth (Hurst et al., 2000). Out of 6 known Chlamydia phages (Sait et al., 2011), the Chlamydia phage DNA has never been detected in either standard or clinical isolates of Chlamydia trachomatis. Of course, the associated phage may be lost during the in vitro growth. Because Chlamydia could not survive outside living cells, it is not possible to use conventional approaches for bacteriophage screening and isolation, such as plaque assays on agar plates. In the present study, we have detected a Chlamydia bacteriophage DNA and antibodies. These results confirmed a possible existence of the Chlamydia phage, as was suggested by a previous study (Garner et al., 2004). The present study provides evidence that a small proportion of $\mathrm{Ct}$ patients is positive for antibodies against the major PhiCPG1 capsid protein VP1. While a few non-Ct controls also showed the presence of such antibodies, the frequency was significantly lower than among patients, and no control samples that gave a positive score in the ELISA test were also positive when examined by Western blot. Through PCR, as a simple means for screening for VP1, we successfully amplified the VP1 DNA fragment in several clinical Ct isolates. These findings provide evidence of the presence of Chlamydia phage capsid protein VP1 in urogenital Ct infection patients. These results suggest that VP1 exists in some Ct patients, and VP1 would be an optimal candidate to detect a putative Chlamydia trachomatis phage.

Further work is needed to verify that the ELISA positives in this study were not the result of, for example, $\mathrm{IgG}$ in human serum or impurities in the recombinant VP1 preparation used to coat the ELISA plates. As a first step towards establishing specificity, Western blotting was used to confirm all ELISA-positive samples (Alonso et al., 1990). In the future studies, we plan to

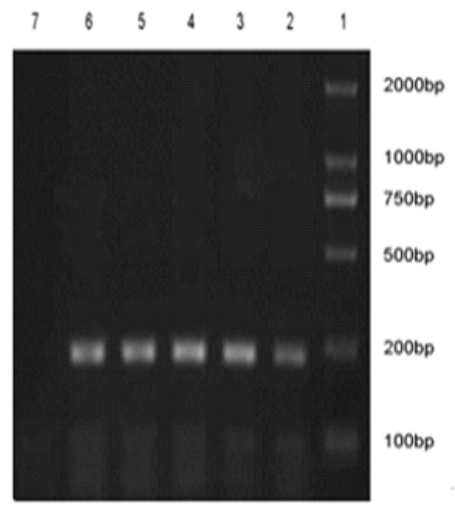

Figure 2. PCR amplification of the VP1 gene in Ct patient swabs 1, molecular base markers. Lanes 2-7, patient swabs. 2-6, PCR positive results. 7, PCR negative result. The 196bp amplified fragment was detected in lanes 2-6. 
expand the number of patients to be screened. Also, positive clinical swabs will be added to the single density McCoy cells and subcultured several times to screen for the Chlamydia bacteriophage capsid protein VP1 antigens in Chlamydia trachomatis using immunofluorescence techniques and electron microscopy.

Our results are consistent with the existence of the Chlamydia phage capsid protein VP1 in patients infected with $\mathrm{Ct}$, which is intriguing given that the phage has yet to be isolated from laboratory or clinical Ct samples. It is possible that previous in vitro studies failed to detect this phage because it is lost during cell culture, especially if the host cells are rapidly destroyed after infection. The molecular and etiological methods developed in this study can be used in future studies to search for a Chlamydia phage and help to elucidate a possible association between the Chlamydia phage and Chlamydia trachomatis.

\section{Acknowledgements}

We acknowledge the generous contributions of the Venereal Disease Research Laboratory of Tianjin Medical University General Hospital, as well as funding from the National Natural Science Foundation of China (VDRL Center for Chlamydia trachomatis Research grant nos. 31100138, 31370211, 81201355).

\section{Conflict of interest}

The authors declare no conflict of interest.

\section{REFERENCES}

Alonso A, Gomes MPD (1990) Detection of foot-and-mouth disease virus infection-associated antigen antibodies: comparison of the enzyme-linked immunosorbent assay and agar gel immunodiffusion tests. Prev Vet Med 9: 233-240.

Bennedsen M, Berthelsen L, Lind I (2002) Performance of three microimmunofluorescence assays for detection of Chlamydia pneumoniae immunoglobulin M, G, and A antibodies. Clin Diagn Lab Immunol 9: 833-839. http://dx.doi.org/ 10.1128/CDLI.9.4.833-839.2002.

Claes G, Vangeluwe D, Van der Sted Y, van den Berg T, Lambrecht B, Marché S (2012) Evaluation of four enzyme-linked immunosorbent assays for the serologic survey of avian influenza in wild bird species. Avian Dis 56: 949-954.

Cohen CR, Nguti R, Bukusi EA, Lu H, Shen C, Luo M, Sinei S, Plummer F, Bwayo J, Brunham RC (2000) Human immunodeficiency virus type 1 -infected women exhibit reduced interferongamma secretion after Chlamydia trachomatis stimulation of peripheral blood lymphocytes. I Infect Dis 182: 1672-1677. http://dx.doi. org/10.1086/317616.

Everson JS, Garner SA, Fane B, Liu BL, Lambden PR, Clarke IN (2002) Biological properties and cell tropism of Chp2, a bacteriophage of the obligate intracellular bacterium Chlamydophila abortus. J Bacteriol 184: 2748-2754. http://dx.doi.org/10.1128/ JB.184.10.2748-2754.2002.
Garner SA, Everson JS, Lambden PR, Fane BA, Clarke IN (2004) Isolation, molecular characterisation and genome sequence of a bacteriophage (Chp3) from Chlamydophila pecorum. Virus Genes 28: 207-214.

Hackett DJ, Zhang C, Stefanescu C, Pass RF (2010) Enzyme-linked immunosorbent assay for measurement of cytomegalovirus glycoprotein B antibody in serum. Clin Vaccine Immunol 17: 836-839. http://dx.doi.org/10.1128/CVI.00422-09. Epub 2010 Mar 10.

Hsia R, Ohayon H, Gounon P, Dautry-Varsat A, Bavoil PM (2000a) Phage infection of the obligate intracellular bacterium, Chlamydia psittaci strain guinea pig inclusion conjunctivitis. Microbes Infect 2: 761-772. http://dx.doi.org/10.1016/S1286-4579(00)90356-3.

Hsia RC, Ting LM, Bavoil PM (2000b) Microvirus of Chlamydia psittaci strain Guinea pig inclusion conjunctivitis: isolation and molecular characterization. Microbiology 146: 1651-1660. http://dx.doi. org/10.1099/00221287-146-7-1651.

Hurst CJ, Lindquist HD: Section I: Structure and Behavior of Viruses: An Introduction. In Viral ecology, Hurst CJ, ed, pp 3-40. San Diego: Academic Press 2000.

Karunakaran KP, Blanchard JF, Raudonikiene A, Shen C, Murdin AD, Brunham RC (2002) Molecular detection and seroepidemiology of the Chlamydia pneumoniae bacteriophage (PhiCpn1). J Clin Microbiol 40: 4010-4014. http://dx.doi.org/10.1128/JCM.40.11.40104014.2002.

Keegan MB, Diedrich JT, Peipert JF (2014) Chlamydia trachomatis Infection: screening and management. I Clin Outcomes Manag 21: 30-38.

Kohlhoff SA, Hammerschlag MR (2015) Treatment of Chlamydial infections: 2014 update. Expert Opin Pharmacother 16: 205-212. http:// dx.doi.org/10.1517/14656566.2015.999041.

Laemmli UK (1970) Cleavage of structural proteins during the assembly of the head of bacteriophage T4. Nature 227: 680-685.

Laughton C (1984) Quantification of attached cells in microtiter plates based on Coomassie brilliant blue G-250 staining of total cellular protein. Anal Biochem 40: 417-423.

Maass M, Harig U (1995) Evaluation of culture conditions used for isolation of Chlamydia pneumoniae. Am J Clin Pathol 10: 141-148.

Marrazzo J, Suchland R (2014). Recent advances in understanding and managing Chlamydia trachomatis infections. F1000 Prime Rep 6: 1-7. http://dx.doi.org/10.12703/P6-120. eCollection 2014.

Nolen BM, Orlichenko LS, Marrangoni A, Velikokhatnaya L, Prosser D, Grizzle WE, Ho K, Jenkins FJ, Bovbjerg DH, Lokshin AE (2013) An extensive targeted proteomic analysis of disease-related protein biomarkers in urine from healthy donors. PLoS One 28: e63368. http://dx.doi.org/10.1371/journal.pone.0063368. Print 2013.

Pawlikowska-Warych M, Śliwa-Dominiak J, Deptuła W (2015) Chlamydial plasmids and bacteriophages. Acta Biochim Pol 62: 1-6. http:/ /dx.doi.org/10.18388/abp.2014_764.

Sambrook J, Fritsch EF, Maniatis T (1989) Molecular cloning: a laboratory manual: 2nd edn. Cold Spring Harbor Laboratory Press, Cold Spring Harbor, NY.

Sait M, Livingstone M, Graham R, Inglis NF, Wheelhouse N, Longbottom D (2011) Identification, sequencing and molecular analysis of Chp4, a novel chlamydiaphage of Chlamydophila abortus belonging to the family Microviridae. Gen Virol 92: 1733-1737. http://dx.doi. org/10.1099/vir.0.031583-0.

Schachter J, Wyrick PB (1994) Culture and isolation of Chlamydia trachomatis. Methods Ensymol 236: 377-390. http://dx.doi. org/10.1016/0076-6879(94)36028-6.

Śliwa-Dominiak J, Suszyńska E, Pawlikowska M, Deptuła W (2013). Chlamydia bacteriophages. Arch Microbiol 195: 765-771. http:// dx.doi.org/10.18388/abp.2014_764. 